\title{
Detecting leakage current by infrared thermography method
}

\author{
M. Riduan B. M. Shariff' ${ }^{1}$, M. F. L. Abdullah'², M. Yusop B. A. Latiff ${ }^{3}$, \\ Ahmad B. Mohamad ${ }^{4}$, Iszaizul B. Ismail ${ }^{5}$ \\ ${ }^{1,2}$ Faculty of Electrical and Electronics Engineering, Universiti Tun Hussein Onn Malaysia (UTHM), Malaysia \\ ${ }^{1,3,4}$ PETRONAS Penapisan (Melaka) Sdn. Bhd., Persiaran Penapisan, Malaysia \\ ${ }^{5}$ Infratech Solutions Sdn. Bhd. Suite 12-14-2, 2nd Floor, Malaysia
}

\begin{tabular}{l} 
Article Info \\
\hline Article history: \\
Received Dec 31, 2018 \\
Revised Apr 21, 2019 \\
Accepted May 11, 2019 \\
\hline
\end{tabular}

\section{Keywords:}

Emissivity

Infrared net radiation power

Oil \& gas

Stefann boltzman

Switchgear

Thermogram

\begin{abstract}
An alternating current leakage can happen in electrical installation such as switchgear panel. If it's not being detected earlier and address properly, it might lead to unintended incident or accident such as fire, electric shock, and power supply trip. Occasionally, if it appears, tracing its root cause can be difficult. The conventional method is by isolating one by one of the electrical loads with aids of multimeter and clamp meter. Unfortunately, this conventional method could be a tedious job for installations involved in numbers of electrical panels. Therefore, an alternative method is deeming necessary. This paper describes research works on Infrared Thermography (IRT) as a new method in detecting leakage current as aids in resolving related electrical problems. The scope of study mingling around to determine IRT's suitable parameters that represent the identification of leakage current, derive new mathematical equation correlating leakage current to IRT and conduct experiment accordingly. Two new equations derived which are leakage current relationship to thermogram and infrared net radiation power. The results of experiment adherence to the hypothesis drawn. Consequently, helps to realize predictive maintenance concept by detecting the root cause of leakage current ahead its triggering points of unintended incident and accident.
\end{abstract}

Copyright (C) 2019 Institute of Advanced Engineering and Science. All rights reserved.

\section{Corresponding Author:}

M. Riduan B. M. Shariff,

Faculty of Electrical and Electronics Engineering,

Universiti Tun Hussein Onn Malaysia (UTHM),

86400 Parit Raja, Batu Pahat, Johor, Malaysia.

Email: he120045@siswa.uthm.edu.my

\section{INTRODUCTION}

Leakage current, like name, suggests some current leaks to ground through a ground conducting path. Electrical equipment commonly includes a grounding system to provide protection against a shock hazard if there is an insulation failure. If no grounding connection, it is the same current flows from any conductive part or the surface of nonconductive parts to ground if conducting path is available (such as the human body). Typical two types of leakage currents namely ac leakage and dc leakage. Dc leakage current usually applies to the end-product equipment caused by dc resistance and capacitances. Meanwhile, ac leakage is a phenomenon of ac current leaking to grounding system caused by a parallel combination of capacitance and direct current resistance between a voltage source (ac line) and the grounded conductive parts of the equipment in which most commonly flows in the insulation surrounding conductors and filters protecting electronic equipment. They also seriously lead to intermittent tripping and rise in voltage on accessible conductive parts become dangerous to living beings resulting in current shock to individuals if no sufficient grounding. In the Oil \& Gas sector, leakage current potential to power losses, power dissipation, equipment tripping, and power supply disturbance [1-4]. Locating the root cause of leakage current is difficult. A common practice is by clamp meter. The common issues are dc offset on higher amperage current probes and small measurement window in 
lower amperage current probes. As known, leakage current will return to the power source through the lowest impedance path that is an alternative path such as metal chassis, enclosure, cabinets, piping and etc.[5]. Therefore, tracing leakage current is not possible by clamp meter. Then how about other voltage detectors such as volt tester? They only work on certain voltage values. Because of conductor associated impedance, be it resistive or reactive, a voltage drop occurs when a current flowing to service entrance ground by low impedance connection. Hence, no dangerous voltage presence during earth fault (leakage current flow) below detection volt tester [6]. That's why the detector based on voltage operated couldn't efficiently detect leakage current. Therefore, this paper presents "Detecting Leakage Current by Infrared Thermography Method" as a novel contribution. In this study, a new technique is proposed; Instead of direct approach that is looking at the leakage current waveforms, this study moving forward with an indirect approach that is looking at the symptom of the leakage currents. The symptom obviously to be studied is heat produced by leakage currents. Heat known as thermal is a potential to study regards to electrical current. It is capable to guide us to their closest location and consequently assist engineers or technicians to resolve any problems related to leakage current even safer, faster and cheaper. There are several tools that could detect heat and for this study, we use infrared thermography (IRT) gun. Actually, this new method purposely to helps engineer in locating root cause of leakage current occur inside switchgear. Massive numbers of circuits mounted on it [7]. It follows by experiment to discover the relevance of newly introduced equation. An experiment conducted in the controlled temperature, humidity and protected from external light contamination that is a source of reflection. It's involved ac current (simulated as leakage current) to be injected to a metal plate as commonly found in electrical switchgear.

Thermography is the practice of quantitatively measuring radiative heat emissions from objects. IRT is a field of science of noncontact measurement approach in getting and process the thermal information [8]. Its basis mount on infrared radiation or in other words electromagnetic radiation which have longer wavelengths compared to visible light. The infrared image that captured by infrared cameras then translated into a visible image according to a specific color for each energy level appears as a fake-color image named as a thermogram [9]. It is capable to detect and sense of electrical problems failure or defect. One of an important point, the heat produced because of resistance materials itself. Since electrons in currents flow through resistance, part of energy converted into heat. This makes it possible to use IRT in sensing electrical problems happened [10-11]. In short, a few kinds of research on IRT for leakage current analysis as follows 1) A nondestructive evaluation of materials by measuring leakage current to check the defect depth despite not knowing its thermal properties and variable surface emissivity [12]. 2) Exact localization of pre-breakdown leakage current distribution in power Schottky diodes [13]. 3) Assess condition of metal-oxide surge arresters via a small resistive leakage current [14-15]. 4) Detection of leakage current in materials of solar cells [16]. 5) Determine ageing of $\mathrm{ZnO}$ materials in gapless surge arresters [17]. 6) Diagnose leakage current of extremely low value by induced temperature variations down to $10 \mu \mathrm{K}$ at a lateral resolution down to $5 \mu \mathrm{m}$ [18]. 7) Interrogate ac earth fault leakage currents by current waveform probed using special low range current transformer on structure of interest and analyze using Fast Fourier Transform [3], [19].

The relationship governing net radiation from hot objects known as Stefan-Boltzmann law as (1) [20]:

$$
P=\varepsilon \sigma A\left(T^{4}-T_{s}^{4}\right)
$$

Where, $\mathrm{P}$ - net radiated power, A- Radiating Area of the object, $\sigma$ - Stefan's constant (5.669 x10-8W/m2K4), $\varepsilon$-Emissivity, T-Temperature of radiating object in $\mathrm{K}, T_{s}$-Temperature of the surroundings [8]. The radiative properties of objects usually described in relation to a perfect blackbody (the perfect emitter). Emitted energy by blackbody denote as Wbb, and normal object at the same temperature as Wobj, then the ratio between these two values describes emissivity $(\varepsilon)$ of the object [20]:

$$
\varepsilon=W o b j / W b b
$$

Thus, emissivity is a number between 0 and 1 . Better radiative properties of the object, the higher its emissivity. An object that has same emissivity $\varepsilon$ for all wavelengths named as grey body. Thus, for grey body, Stefan-Boltzmann's law takes form according (3) [20];

$$
\mathrm{W}=\varepsilon \sigma \mathrm{T} 4(\mathrm{~W} / \mathrm{m} 2)
$$

Which states total emissive power of a grey body is same as that of a blackbody of same temperature reduced in proportion to value of $\varepsilon$ for the object. Still, most bodies are neither blackbodies nor grey bodies. The emissivity varies with wavelength. As thermography operates only inside limited spectral ranges, in practice it is often possible to treat objects as grey bodies. In any case, an object having emittance that varies 
strongly with wavelength is called a selective radiator [21]. Wien's displacement law is a law that states that there is an inverse relationship between the wavelength of the peak of the emission of a black body and its temperature. A black body is an object that absorbs all electromagnetic radiation that falls onto it. No radiation passes through it and none are reflected. Despite the name, black bodies are not actually black as they radiate energy as well since they have a temperature larger than $0 \mathrm{~K}$. The law states [20]:

$$
\lambda_{\max }=b / T
$$

Where, $\lambda_{\max }$ is the peak wavelength $(\mathrm{nm}), \mathrm{T}$ is the temperature of the blackbody $(\mathrm{K})$ and $\mathrm{b}$ is Wien's displacement constant, $2.898 \times 10^{6}$ (rounded) $(\mathrm{nm} \cdot \mathrm{K})$. Wien's law states the hotter an object is, the shorter the wavelength at which it will emit most of its radiation [20].

Watt (W) is the electrical unit of electric power. It measures the rate of consumed energy. This energy feed by combination of electric current and electric potential that is delivered by circuit. Electrical energy can always be called another type of energy (heat, light, motion, etc.). Those explanation described by (5) [22]:

$$
\begin{aligned}
& 1 \mathrm{~W}=1 \text { Volt } \times 1 \text { Ampere } ; \quad 1 \mathrm{~W}=1 \mathrm{~J} / 1 \mathrm{~s} ; \quad \text { Energy = Power } \mathrm{x} \text { Time; } \\
& 1 \mathrm{Ws}=1 \mathrm{~J}
\end{aligned}
$$

It is important precisely to define the difference between heat and temperature. Often, these two elements were being misunderstood conceptually. Heat is defining as the molecules' total kinetic energy of the materials or substance. Heat is one form of energy. Any matter can contain heat or other words called as thermal energy [23]. Then, how about the temperature? Temperature is defining as atoms' and molecules' the average speed of the materials or substance. Temperature is not a form of energy. Temperature is implication of thermal energy or heat. So, as the heat of an object increase, proportionally temperature increases and vice versa. Easy to say that, cooler temperature means molecules move slower and vice versa [23]. The matter will absorb energy. Absorbed energy could be interpreted as the amount of heat needed to raise the temperature of a material. Because substances all heat differently, different amounts of heat needed in making a temperature change. The specific heat capacity of a substance is a quantity of heat needed to raise the temperature of a unit quantity of the substance by one degree. Calling the amount of heat added $\mathrm{Q}$, which will cause a change in temperature $\Delta \mathrm{T}$ to a weight of substance $\mathrm{W}$, at a specific heat of material, $\mathrm{Cp}$ [24] and this relationship could be represented by the following equation:

$$
\mathrm{Q}=\mathrm{m} \cdot \mathrm{Cp} \cdot \Delta \mathrm{T}
$$

Where; $\mathrm{Q}=$ Heat Required to Raise Temperature of Materials During Heat-Up (Ws); $\mathrm{m}=$ Weight of Material $(\mathrm{g}) ; \mathrm{Cp}=$ Specific Heat of Material $\left(\mathrm{J} / \mathrm{g} \bullet{ }^{\circ} \mathrm{C}\right) ; \Delta \mathrm{T}=$ Temperature Rise of Material $\left(\mathrm{T}_{\text {Final }}-\mathrm{T}_{\text {Initial }}\right)\left({ }^{\circ} \mathrm{C}\right)$.

\section{RESEARCH METHOD}

This subtopic figures out on exploration linking chain relationship between leakage current those travel through switchgear structure with the temperature it's prov0duced so. Anyhow to set up the foundation of our understanding; it needs us to synthesize theories which are electrical power concept with the idea of heat and temperature. Once a great understanding is in place, then it will be easier for us in developing a new equation or formula that can represent the relationship behavior correlating electrical leakage current and heat cum temperature.

\subsection{Derivation equation correlating leakage current to thermogram}

Since all calculations are in watts, an additional conversion of $1 \mathrm{~J}=1 \mathrm{Ws}$ is introduced yielding. Also, to suit with experiment, $T_{\text {Initial }}$ is consider equal as $T_{\text {No Leakage, while }} T_{\text {Final }}$ can consider as $T_{\text {Leakage. }}$ Where $T_{\text {No }}$ Leakage is temperature of the materials during no leakage current passes through it. While, $\mathrm{T}_{\text {Leakage }}$ is temperature of materials during leakage current passes through it. Then, write back Error! Reference source not found.) above as:

$$
\mathrm{Q}=\mathrm{m} \cdot \mathrm{Cp} \cdot\left(\mathrm{T}_{\text {Leakage }}-\mathrm{T}_{\text {No Leakage }}\right)
$$

Now it is already known that electrical energy represents by the famous (8);

$$
E=I^{2} \cdot R \cdot t
$$


Where; $\mathrm{E}=$ Electrical Energy (Ws); $\mathrm{I}=$ Current $(\mathrm{A}) ; \mathrm{R}=$ Resistance $(\Omega)$; $\mathrm{t}=$ Time (s);

While for the specific heat capacity of the materials takes the form as described in (7) previously. Obviously, the unit for electrical energy and specific heat equation is same which is Watt-second (Ws). To allow us to derive a new equation relating these two entities; it is must to ensure the unit and intention of the formula are the same. The good thing that these equations comply with this requirement. Now, these two equations which are (7) and (8) could be synthesized to derive new equation as follow:

$$
\mathrm{I}^{2} \cdot \mathrm{R} \cdot \mathrm{t}=\mathrm{m} \cdot \mathrm{Cp} \cdot\left(\mathrm{T}_{\text {Leakage }}-\mathrm{T}_{\text {No Leakage }}\right)
$$

Hence, we could rearrange the (9) above into;

$$
\mathrm{T}_{\text {Leakage }}=\left(\mathrm{I}^{2} \cdot \mathrm{R} \bullet \mathrm{t} / \mathrm{m} \cdot \mathrm{Cp}\right)+\mathrm{T}_{\text {No Leakage }}
$$

From new (10) derived above, clearly to us that if the following parameters are known e.g. resistance of the object (in this case metal plate) $\mathrm{R}$ in ohm $(\Omega)$, leakage current flow through the object, I in Ampere (A), time, $\mathrm{t}$ in second (s), weight of the object, $\mathrm{m}$ in gram (g), specific heat capacity of object $\mathrm{Cp}$ in Watt-second

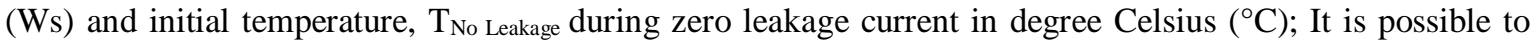
know the temperature under influence of leakage current that will appear in thermogram later. Please note that, this new equation or formula dedicated for metal plate with the thickness of sample in this experiment purposely to define correlation between leakage current versus temperature of the object. As we know earlier that for a grey body, Stefan-Bolzmann's law takes the form as (3) earlier. It is possible for us to correlate between net energy radiation emitted by the surface object to the leakage current travel through the object. Another synthesization happen here between the new derive (10) earlier with the Stefan-Bolzmann's law that

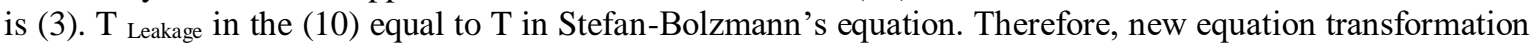
takes the form (11):

$$
\mathrm{T}=(\mathrm{W} / \varepsilon \sigma)^{1 / 4}
$$

In other hand, equation (10) could be hybrid with equation (11) where another new equation rises as;

$$
\mathrm{W}=\left[\left(\mathrm{I}^{2} \cdot \mathrm{R} \bullet \mathrm{t} / \mathrm{m} \cdot \mathrm{Cp}\right)+\mathrm{T}_{\text {No Leakage }}\right]^{4} \cdot \varepsilon \sigma
$$

This new derived equation tells us that the infrared net radiation power is proportional with leakage current, materials resistance, time to reach temperature equilibrium as well as emissivity of the object. But inversely for weight and specific heat capacity of materials. Later we'll plot both of (10), (12) and compare them with actual results from our experiment.

\subsection{Experimental}

Our first main assumption for this experiment is controlled environment in term of surrounding temperature and humidity. Also, it must cover from the external source of radiation. Due to probing the surface temperatures of the sample, it is also closely related to heat flows. Though heat flow is closely linked to energy use, other thermal characteristics such as condensation and thermal comfort are closely linked to surface temperatures [25]. So, these are a few factors to be fixed. Also, it is necessary to prevent surface condensation, which will alter surface emittance and affect performance [25]. In conjunction, our first hypothesis based on (10), say that temperature caused by leakage current is linear relationship as well applies to infrared net radiation power. Then second hypothesis is time for the energy to reach its equilibrium temperature (heat energy distributed evenly to most molecules) also playing a big role. This time is taken not from zero leakage current, but time required during transition from one level of leakage current to upper level with consistent interval that is in our study 1 Ampere interval of injected leakage current chosen. This is merely due to during zero leakage current, it is meaning no heat energy transfer to the materials. To study the idea of detecting leakage current using IRT technique; it is better to start with a small and straightforward sample. Reflect to purpose of this study; is to detect leakage current travel through structure which specifically metal plate that being used to mount electrical apparatus on it. In this experiment, same metal plate to be used but in scaling down size from the original mounting plate. We prepared piece of sample to be study which is metal plate with $1 \mathrm{~mm}$ thickness come with dimension $1.7 \mathrm{~cm}(\mathrm{~W}) \times 5 \mathrm{~cm}(\mathrm{~L})$. Thermography container must be built at the first place. Setup experiment arrangement as Figure 1.

Before start experiment, there are a few parameters to figure out before plotting our new equations. They are specific heat of materials, sample weights, sample resistance, time to reach equilibrium temperature (i.e. temperature become stagnant at certain value). Also, not to forget initial temperature of the samples (prior 
to injecting leakage current). See Table 1 for the mentioned parameters and afterwards plot the graph as to be see in latter section. Start experiment by probe the room temperature, humidity as well inside thermography container. Arrange sample by applying crocodile clips from current injector. In simulating leakage current, it is the best to inject from left (red color) to right (black color) of sample as nature of X-axis in Figure 1. Simulated leakage current by start with $1 \mathrm{~A}, 50 \mathrm{~Hz}$ for a few minutes until reach equilibrium state waiting the complete warming of sample [26]. Once the sample reaches thermal equilibrium state, use IRT gun to capture thermogram. Repeat the same steps for rest. For our research here, the qualitative means look at overall trends and patterns. While, quantitative means, to seek the minimum, maximum and average value of temperature resultants of the leakage current injected [23].

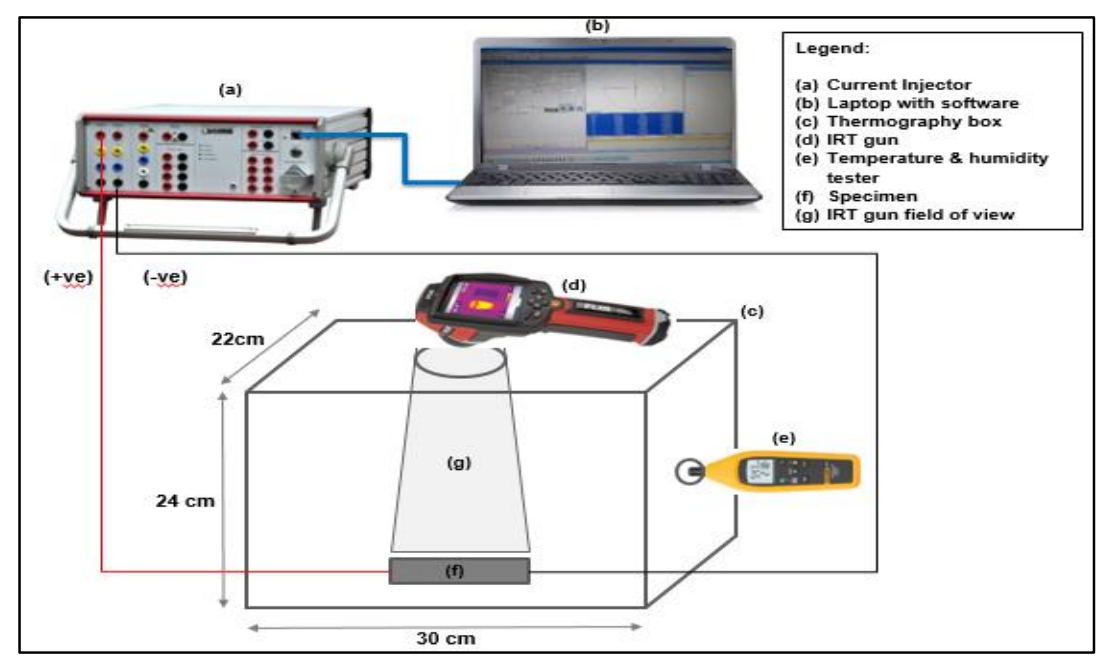

Figure 1. Leakage current experiment setup

Table 1. Parameter prior start experiment

\begin{tabular}{cc}
\hline Parameter & Measured Value \\
\hline Specific heat of materials, $\mathrm{Cp}\left(\mathrm{J} / \mathrm{g} \cdot{ }^{\circ} \mathrm{C}\right)$ & 0.5107896 \\
Weight, $\mathrm{m}(\mathrm{g})$ & 6.02 \\
Resistance, $\mathrm{R}(\Omega)$ & 0.2 \\
Time, $\mathrm{t}(\mathrm{s})$ & 3 \\
Initial temperature, $\mathrm{T}_{\text {No Leakage }},\left({ }^{\circ} \mathrm{C}\right)$ & 32.4 \\
\hline
\end{tabular}

\section{RESULTS AND ANALYSIS}

Results of experiment's thermal image shown in Figure 2. They are under influence of leakage current 4 Ampere (left) and 5 Ampere (right). During no leakage current applied, whole surface of sample be at same temperature. In conjunction means all sample's molecules absorbed even amount of heat. Once leakage current applied, tiny parts of sample get hotter. This strongly believe there is small area with uneven density of metal composition; where more metal, more molecules, more receiving heat energy, more speed of molecules lead to higher temperature. The profile analysis shows temperature declining while move away from entry point of leakage current. The rate of falls is in $1^{\circ} \mathrm{C}$ per $\mathrm{cm}$. Anyhow, temperature rises again towards leakage current exit point. Since beginning, significant changes remarks on the hottest spot. At 1 to 4 Ampere current injected; The hottest spot lies somewhere at exit point of leakage current (refer to red colour tiny triangle). Surprisingly, at 5 Ampere and above the said spot moves to entry point. Look closely on the thermogram where there is a path pattern. It is depending on intensity of sample's molecules, in which indirectly influence heat energy distribution and temperature produced. Also, observe the edge area have lower temperature. It is obviously can see like yellow aura surrounding sample. This happens because of its nature of side which intersection of two different axis. So, more heat losses in this area compare to the middle part of the sample penetrated by leakage current. Maybe, in the future research, it is great if could significantly consider the image processing technique as a hybrid with IRT technique in improvising this method. Crocodile clip itself much lower temperature compare to others. Of course, it should be like this. Usually, any electrical mingling with conductivity, connection and terminal comes with great condition. That termination must adhere to satisfactory lowest resistance in line with necessary to minimize loses and be more efficient. 

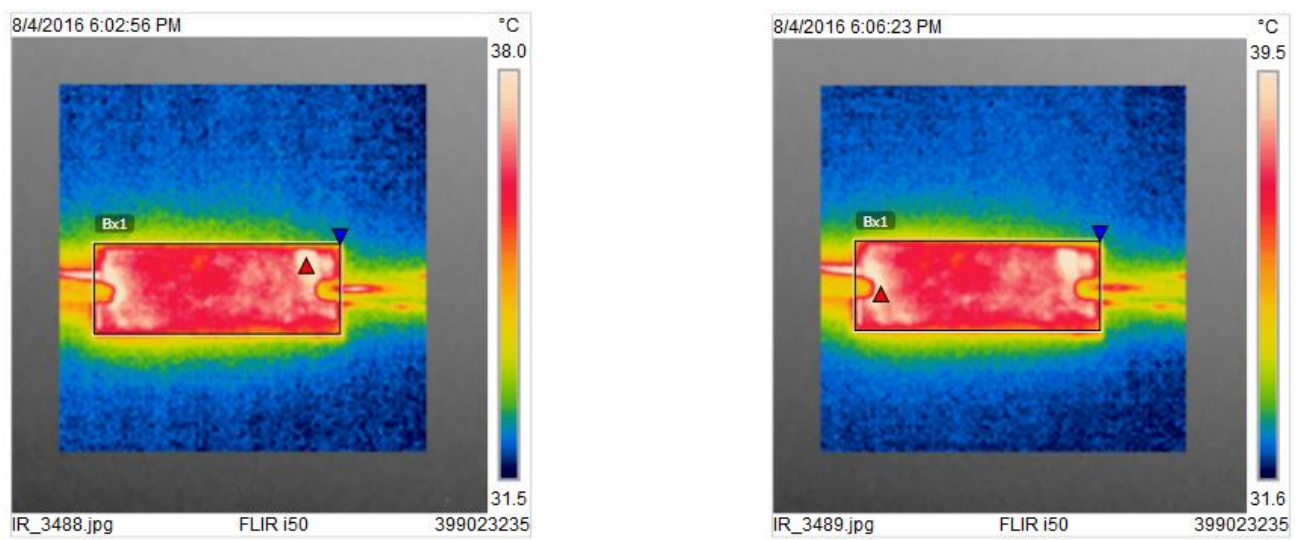

Figure 2. Thermogram results

The results tabulated in Error! Reference source not found., translated into the graphs as showing in Figure 3. They strongly support our earlier first hypothesis where temperature behave linearly with increase of leakage current. If look carefully at the graphs, the actual temperature is slightly higher about $2 \%$ than the (10) from no leakage current until 5 Ampere. But after that its drop below (10) for about 6\% until 8 Ampere. This is merely influence of the atmospheric surround the sample [23]. The atmosphere is a transmissive object between the target and the IRT camera [23]. It transmits most of the radiation from the target and absorbs small parts of the exitant radiation from the target [23]. So, there is a small loss, as the exitant radiation from the target passes through the atmosphere [23]. The heat generated by the sample indirectly vary a bit on air temperature and relative humidity near surface atmospheric of sample itself. In conjunction, infrared radiation emitted by sample deviate a bit attenuated and cause little deviation of temperature results. This condition can be fixed by tuning those related parameters in IRT gun to get the effects of atmosphere are taken off. Addressing to second hypothesis which is time between state of level leakage current being injected at same interval. The result encouragingly, because time recorded is 3 seconds for all range of leakage current. Our last hypothesis which is related to (12) shown in Figure 3 clearly that the graphs shape, trend and pattern is just about the same with (10) graph mentioned earlier. Bigger the leakage current, the object emitted more IRT power. Lighter the sample become hotter and consequently produce more IRT power. It is interesting the intersection between these two graphs occur at same point for both equations. It is concrete evidence that the (10) and (12) can be embedded into IRT gun and translate thermogram into leakage current value accordingly for instant acknowledgement by user. Hence, it is full-filled our objective to make IRT method significant and relevant for detecting leakage current.

Table 2. Computation and actual data

\begin{tabular}{|c|c|c|c|c|c|c|c|c|c|c|c|c|c|}
\hline \multirow{2}{*}{$\begin{array}{l}\mathrm{I} \\
(\mathrm{A})\end{array}$} & \multirow{2}{*}{$\begin{array}{c}\mathrm{R} \\
(\Omega)\end{array}$} & \multirow{2}{*}{$\begin{array}{l}M \\
(\mathrm{~g})\end{array}$} & \multirow{2}{*}{$\mathrm{C}_{\mathrm{p}}$} & \multirow{2}{*}{$\begin{array}{c}{ }^{*} \mathrm{~T}_{\mathrm{No}} \\
\text { Leakage } \\
\text { Current } \\
\left({ }^{\circ} \mathrm{C}\right) \\
\end{array}$} & \multirow{2}{*}{$\mathrm{I}^{2} \mathrm{Rt}$} & \multirow{2}{*}{$\mathrm{mCp}$} & \multirow{2}{*}{$\begin{array}{c}\mathrm{I}^{2} \mathrm{Rt} / \mathrm{m} \\
\mathrm{C}_{\mathrm{p}}\end{array}$} & \multirow{2}{*}{$\begin{array}{c}\mathrm{T}_{\text {Leakage }} \\
\text { current } \\
\text { by }(10) \\
\left({ }^{\circ} \mathrm{C}\right)\end{array}$} & \multirow{2}{*}{$\begin{array}{l}\mathrm{W}_{\text {Infrared }} \\
\text { Radiation } \\
\text { by }(12) \\
\left(\mathrm{W} / \mathrm{m}^{2}\right) \\
\end{array}$} & \multirow{2}{*}{$\begin{array}{l}\mathrm{W}_{\text {Infrared }} \\
\text { Radiation } \\
\text { Actual } \\
\left(\mathrm{W} / \mathrm{m}^{2}\right) \\
\end{array}$} & \multicolumn{3}{|c|}{$\begin{array}{c}\text { Thermogram } \\
\text { (Actual Temperature) }\end{array}$} \\
\hline & & & & & & & & & & & $\begin{array}{l}\text { File } \\
\text { No. }\end{array}$ & $\left({ }^{\circ} \mathrm{C}\right)$ & $\begin{array}{c}\Delta \\
(\%)\end{array}$ \\
\hline 0 & 0.2 & 6.02 & 0.511 & 32.4 & 0 & 3.075 & 0.000 & 32.4 & 0.0562 & 0.0563 & $\begin{array}{c}\text { File no. } \\
3481\end{array}$ & 32.5 & 0.3 \\
\hline 1 & 0.2 & 6.02 & 0.511 & 32.4 & 0.6 & 3.075 & 0.195 & 32.6 & 0.0576 & 0.0583 & $\begin{array}{c}\text { File no. } \\
3485\end{array}$ & 32.8 & 0.6 \\
\hline 2 & 0.2 & 6.02 & 0.511 & 32.4 & 2.4 & 3.075 & 0.780 & 33.2 & 0.0618 & 0.0650 & $\begin{array}{l}\text { File no. } \\
3486\end{array}$ & 33.7 & 1.6 \\
\hline 3 & 0.2 & 6.02 & 0.511 & 32.4 & 5.4 & 3.075 & 1.756 & 34.2 & 0.0694 & 0.0757 & $\begin{array}{c}\text { File no. } \\
3487\end{array}$ & 35 & 2.5 \\
\hline 4 & 0.2 & 6.02 & 0.511 & 32.4 & 9.6 & 3.075 & 3.122 & 35.5 & 0.0812 & 0.0886 & $\begin{array}{l}\text { File no. } \\
3488\end{array}$ & 36.3 & 2.2 \\
\hline 5 & 0.2 & 6.02 & 0.511 & 32.4 & 15 & 3.075 & 4.878 & 37.3 & 0.0985 & 0.1009 & $\begin{array}{l}\text { File no. } \\
3489\end{array}$ & 37.5 & 0.6 \\
\hline 6 & 0.2 & 6.02 & 0.511 & 32.4 & 21.6 & 3.075 & 7.024 & 39.4 & 0.1233 & 0.1031 & $\begin{array}{c}\text { File no. } \\
3491\end{array}$ & 38 & -3.6 \\
\hline 7 & 0.2 & 6.02 & 0.511 & 32.4 & 29.4 & 3.075 & 9.561 & 42.0 & 0.1582 & 0.1373 & $\begin{array}{c}\text { File no. } \\
3492\end{array}$ & 40.6 & -3.2 \\
\hline 8 & 0.2 & 6.02 & 0.511 & 32.4 & 38.4 & 3.075 & 12.488 & 44.9 & 0.1588 & 0.1588 & $\begin{array}{c}\text { File no. } \\
3493\end{array}$ & 42 & -6.4 \\
\hline
\end{tabular}




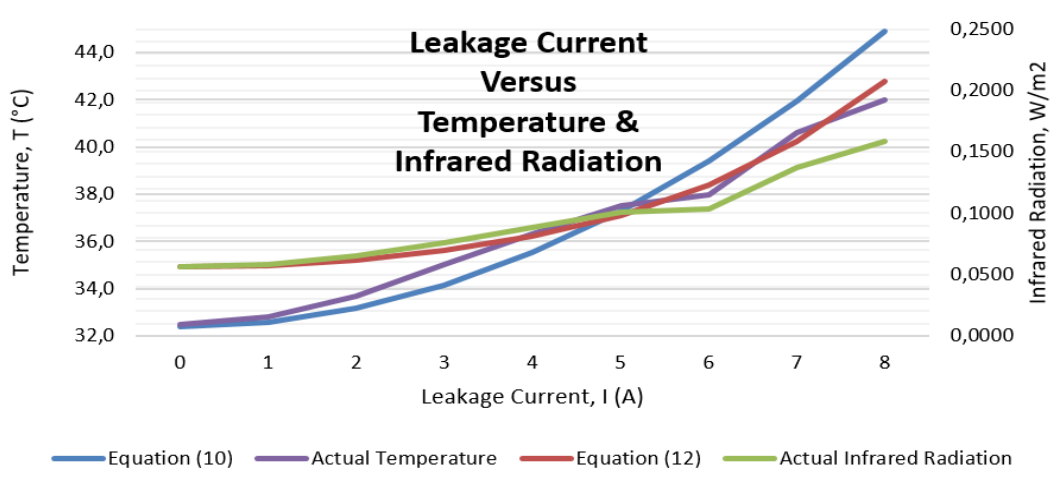

Figure 3. Graph plot experiment results

\section{CONCLUSION}

The resultants of experiment adhering to hypothesis drawn earlier that are: 1) Leakage current is in linear relationship with temperature. 2) Even distribution of heat to whole sample's molecules depending on time to reach equilibrium temperature. 3) Heavier sample affecting less hot. 4) Temperature during no leakage current required as benchmark. 5) IRT power emitted is linearly dependent with emissivity of the surface object. In addition, indeed new derived equation before, are valid, novelty and significant contribution to the field of thermographic from perspective of electrical. It does means that, interrogate of electrical defects or problems or issues although at the first time of our investigation is possible although in situation where baseline data unavailable at our hand. This is a happy news especially for maintenance people. In some circumstance, the electrical installations quite ageing and sometimes no any drawings available and the problems sign shows after many years in operation. The method describes in this study not only can be used for detecting leakage current spreading on structure but also could be utilized at any electrical installation that has electron flows through as long the needful parameters as mentioned before being determined such as knowing the overload condition, or at what capacity of equipment operation. Also, the extensive details research could be fine tuning these new equations to get better accuracy reflecting the applications needs as well to be embedded in automatic algorithm for software application that capable to forecast or predict the value of leakage current flow through. Absolutely, this novel method has great potential to boost market demands of IRT tools in the future.

\section{ACKNOWLEDGEMENTS}

The author would like to acknowledge Universiti Tun Hussein Onn Malaysia, Malaysian Refining Company Sdn. Bhd. and PETRONAS Penapisan (Melaka) Sdn. Bhd. for providing opportunity and technical support towards accomplishment of this research.

\section{REFERENCES}

[1] N. B. Romli, K. N. Minhad, M. B. I. Reaz, and M. S. Amin, “An overview of power dissipation and control techniques in cmos technology,” J. Eng. Sci. Technol., vol. 10, no. 3, pp. 364-382, 2015.

[2] I. Condor D.C. Power Supplies, “Condor Application Note 7/01 Leakage Current," 2003. [Online]. Available: www.condorpower.com. [Accessed: 27-Jul-2015].

[3] M. R. B. M. Shariff, M. F. L. Abdullah, M. Y. B. A. Latiff, G. B. M. Tion, Z. A. Haron, and A. Johari, "Impact of EMI Filter installed in AC UPS System to Earth Leakage Current," in 2014 IEEE 8th International Power Engineering and Optimization Conference (PEOCO2014), Langkawi, The Jewel of Kedah, Malaysia., 2014, no. March, pp. 647-652.

[4] A. P. Kumar, B. L. V. S. S. Aditya, G. Sony, C. Prasanna, and A. Satish, "Estimation of power and delay in CMOS circuits using LCT,” Indones. J. Electr. Enginering Comput. Sci., vol. 14, no. 2, pp. 990-998, 2019.

[5] J. M. Russell, "Leakage and Ground Currents : Measurement Techniques." PowerLines, West Hartford, CT 06133 0025, pp. 1-9, 2005.

[6] Elya B. Joffe \& Kai-Sang Lock, Grounds for Grounding: A Circuit-to-System Handbook, 1st ed. Hoboken, New Jersey.: John Wiley \& Sons, Inc., 2010.

[7] NEMA Standards Publication 250-2003, "NEMA Enclosure Types." National Electrical Manufacturers Association, Rosslyn, VA 22209, pp. 1-9, 2005.

[8] Z. Azmat and D. J. Turner, "Infrared thermography and its role in rural utility environment," p. B2/1-B2/4, 2005.

[9] P. Venegas, J. Guerediaga, L. Vega, and J. Molleda, "Infrared Thermography for Temperature Measurement and Non-Destructive Testing," Sensors, vol. 14, pp. 12305-12348, 2014. 
[10] A. G. Corporate, C. Kolakowski, and R. C. Manager, "Infrared Thermography: Determining failure or problems in electrical systems," 2011.

[11] Infraspection Institute, "Standard for Infrared Inspection of Electrical Systems \& Rotating Equipment," 425 Ellis Street Burlington, NJ 08016, 2008.

[12] R. G. and S. Tuli, "Electrical approach to defect depth estimation by stepped infrared thermography," in IEE Proc.Sci. Meas. Technol, 2004, vol. 151, no. 4, pp. 298-304.

[13] M. Riccio, A. Irace, and G. Breglio, "Lock-in thermography for the localization of prebreakdown leakage current on power diodes," in 2009 Ph.D. Research in Microelectronics and Electronics, PRIME 2009, 2009, pp. 208-211.

[14] Z. Abdul, N. Bashir, and N. Asilah, "Jurnal Teknologi Full paper Thermal Image and Leakage Current Diagnostic as a Tool for Testing and Condition Monitoring of ZnO Surge Arrester," vol. 4, no. Figure 1, pp. 27-32, 2013.

[15] W. A. M. Ursine, J. L. Silvino, L. G. Fonseca, and R. M. De Andrade, "Metal-oxide surge arrester's leakage current analysis and thermography," in 2013 International Symposium on Lightning Protection, SIPDA 2013, 2013, pp. 297-303.

[16] Y. Hu, "High-Resolution Lock-in Thermography Investigation on Industrial Multicrystalline Silicon Solar Cells," IEEE J. PHOTOVOLTAICS, vol. 3, no. 3, pp. 952-956, 2013.

[17] Y. Novizon and A.-M. Zulkurnain, "Correlation between third harmonic leakage current and thermography image of zinc oxide surge arrester for fault monitoring using artificial neural network," Appl. Mech. Mater., vol. 554, pp. 598-602, 2014.

[18] S. Huth, O. Breitenstein, and A. Huber, "Lock-in IR-thermography-A novel tool for material and device characterization," 2002.

[19] M. R. Mohd Shariff, M. F. L. Abdullah, Z. A. Haron, A. Johari, M. Y. A. Latiff, and N. E. M. Isnain, "Earthing Current Signature Analysis in resolving Motor Protection Relay communication fault," in Conference Proceeding 2014 IEEE International Conference on Power and Energy, PECon 2014, 2014, pp. 400-405.

[20] Flir Systems, The Ultimate Infrared Handbook for $R \&$ D Professionals, Rev. 12/12. Wilsonville, USA: FLIR System Incorporated, 2012.

[21] Flir, The Ultimate Infrared Handbook for R\&D Professionals. FLIR AB, 2013.

[22] A. R. Hambley, Electrical Engineering Principles and Applications, SECOND EDI. Upper Saddle River, New Jersey 07458: Prentice-Hall, Inc, 2002.

[23] M. M. Cronholm, ITC INFARED THERMOGRAPHY LEVEL 1-COURSE MANUAL. Stockholm, Sweden: Infrared Training Centre.

[24] WATLOW, WATLOW Heaters User's Guide. St. Louis, Missouri, United States: WATLOW, 2015.

[25] D. Türler, B. T. Griffith, and D. K. Arasteh, "Laboratory Procedures For Using Infrared Thermography To Validate Heat Transfer Models," California, USA, This work was supported by the Assistant Secretary for Energy Efficiency and Renewable Energy, Office of Building Technology, State and Community Programs of the U.S. Department of Energy under Contract No. DE-AC03-76SF00098., 1997.

[26] D. Vâr, V. E. Ilian, and M. Bâzu, "Thermographic analysis with enhanced emissivity," in Proceedings of the International Semiconductor Conference, CAS (2014), 2014, no. 2, pp. 283-286. 